\title{
A Novel Fluorobenzyl Polyethylene Glycol Conjucated Tetraiodothyroacetic Acid (fb-PMT), Targeting Thyrointegrin av $\beta 3$ in Treatment Acute Myeloid Leukemia
}

\section{Noureldien H. E. Darwish}

Albany College of Pharmacy and Health Sciences https://orcid.org/0000-0002-4124-9772

Gennadi V. Glinsky

University of California San Diego Institute of Engineering in Medicine

\section{Thangirala Sudha}

Albany College of Pharmacy and Health Sciences

Shaker A. Mousa ( $\square$ shaker.mousa@acphs.edu )

The Pharmaceutical Research Institute Albany College of Pharmacy and Health Sciences https://orcid.org/0000-0002-9294-015X

\section{Research}

Keywords: Acute Myeloid Leukemia (AML), Thyrointegrin avß3, SNA1, RB1, MAML1, IRF9, HIF1A, MYC, TWIST1, TFAP2C

Posted Date: August 3rd, 2021

DOI: https://doi.org/10.21203/rs.3.rs-754222/v1

License: () (1) This work is licensed under a Creative Commons Attribution 4.0 International License. Read Full License 


\section{Abstract}

Background: Acute myeloid leukemia (AML) is associated with poor long-term survival, even with newer therapeutic agents. Here we show the results of our pre-clinical study, in which we evaluate the efficacy of a new thyrointegrin av $\beta 3$ antagonist, named fluorobenzyl Polyethylene glycol conjucated tetraiodothyroacetic acid (fb-PMT).

Methods and Results: fb-PMT effectively suppresses the malignant growth of human acute myeloid leukemia (AML) after successful engraftment in transgenic NSG-S xenograft mouse models of either established human AML cell line or primary AML cells. Daily treatment with fb-PMT (1-10 mg/kg body weight) subcutaneously (s.c.) for 3-4 weeks was associated with marked regression of leukemogenesis and extended survival in both models. The efficiency of the fb-PMT therapy was verified using IVIS imaging, flowcytometry and histopathological examination to monitor the engraftment of leukemic cells in the bone marrow and other organs. fb-PMT therapy for $3-4$ weeks at 3 and $10 \mathrm{mg} / \mathrm{kg}$ daily doses exhibited significant reduction $(P<0.0001)$ of leukemic cell burden of $74 \%$ and $>95 \%$, respectively. All fb-PMT-treated mice in the $10 \mathrm{mg} / \mathrm{kg}$ treatment arm successfully maintained remission after discontinuing the daily treatment. Comprehensive fb-PMT safety assessments demonstrated excellent safety and tolerability at multiple folds above the anticipated human therapeutic doses. Lastly, our genome-wide microarray screens demonstrated that fb-PMT works through the molecular interference mechanism with multiple signaling pathways contributing to growth and survival of leukemic cells.

Conclusion: our preclinical findings of the potent anticancer activities of fb-PMT and its favorable safety profiles warrant its clinical investigation for the effective and safe management of AML.

\section{Background}

Acute myeloid leukemia (AML) is one of the most aggressive malignant hematological disorders. More than 19,000 new cases were estimated to occur in the United States in 2020 (1.1\% of all new cancer cases) [1]. In 2020, the estimated number of deaths from AML is 11,180 , which represent $56 \%$ of new cases (1.8\% of all cancer deaths), with an overall 5 -year survival rate of $27.4 \%$ [1]. Current treatment regimens for AML include traditional chemotherapy, allogeneic hematopoietic cell transplantation, and targeted therapies for specific mutations in limited numbers of AML patients, all of whom still suffer from adverse effects and relapse. New broad spectrum effective and safe treatment options are urgently needed for the different types of AML.

AML is now curable in up to $40 \%$ of patients under the age of 60 years and in up to $15 \%$ of patients over the age of 60 . In elderly patients who are unable to tolerate the available chemotherapy, mean survival is 5-to-10 months [2]. Important advances in defining the 'genomic landscape' of AML have enabled the prognostic classification of the disease and, to some extent, have facilitated the choice of chemotherapeutic agents. Among the mutations of particular interest and importance in AML are those of the FLT3, NPM, CEBPA, KIT, NRAS, IDH1/2, and TP53 genes [2]. Targeted therapies for specific mutations in treating AML were recently approved by the FDA based on the genetic basis of the disease in different subsets of AML patients. However, those targeted therapies treat only a small percentage of the AML population and patients suffer from relapse upon discontinuation of treatment[3].

On the other hand, crosstalk between leukemic cells and the bone marrow microenvironment is recognized as one of important factors that keeps leukemic cells in quiescent state and helps them to escape the different therapies. One of the functionally important entities in the bone marrow microenvironment is represented by the integrins. Integrins are a family of heterodimeric structural proteins of the plasma membrane that are important to cell-cell interactions and cell motility $[4,5]$. They are critical to leukocytes' function and to the angiogenesis process, particularly local release of growth factors that are generously overexpressed and produced by cancer cells and by dividing endothelial cells of tumor-relevant blood vessels. There are different members of Integrin family including av $\beta 3$, av $\beta 5$, and a5 $\beta 1$ which involved in angiogenesis and have high affinity to arginine-glycine-aspartate (RGD) extracellular matrix (ECM)- containing angiogenesis modulators such as fibronectin, fibrinogen and osteopontin [6-8]. av $\beta 3$ (thyrointegrin) is generously expressed by cancer cells and by dividing endothelial cells. Mechanistically, thyrointegrin av $\beta 3$ enhances $\beta$-catenin signaling and the tyrosine kinase activities in AML $[9,10]$. Integrin av $\beta 3$ was reported to be highly expressed in AML and associated with poor outcomes $[11,12]$.

This study focused on comprehensive preclinical evaluations of anticancer activities of a novel thyrointegrin av $\beta 3$ antagonist, fb-PMT in models of AML. Mechanistically, fb-PMT and similar molecules bind to a specific site on thyrointegrin av $\beta 3$ receptors that can be blocked with high affinity by various triazole tetrac derivatives [13-16]. Our genome-wide microarray screens demonstrated that fb-PMT appears to exert its potent anticancer actions on human AML through a molecular interference mechanism with multiple signaling pathways supporting growth and survival of leukemic cells.

Page 2/22 


\section{Materials And Methods \\ Tumor cells and test compound}

AML cell lines (K562-Luc; human erythroleukemia cells and KG1a; human myelocytic leukemia cells) were obtained from American Type Culture Collection (ATCC, Manassas, VA, USA). These cell lines are commonly used in research studies as experimental AML models. Primary human AML cells (De novo AML 6373, harboring FLT3-ITD mutation) were collected by leukapheresis from AML patients at the University Hospital, University of Pennsylvania, with informed consents (IRB protocol 703185).

The K562 cells were established from a chronic myeloid leukemia female patient 'in blastic crisis and expressing P210 bcr-abl mutation $[17,18]$. Morphologically, K562 cells represent undifferentiated, nongranulated blast cells with a basophilic cytoplasm with two or more prominent nucleoli. The K562 cells are strongly reactive for acid phosphatase while negative for other cytochemical markers. K562-Luc cells were maintained in RPMI 1640 (Roswell Park Memorial Institute) media supplemented with 10\% fetal bovine serum (FBS). To maintain luciferase labeled cells, blasticidin antibiotic was added at a concentration of $8 \mu \mathrm{g} / \mathrm{mL}$.

KG1a cells were first isolated from a male patient with AML in 1980 [19]. KG1a cells are unable to differentiate into functionally mature cells and remain in an early or primitive state of differentiation. Cytogenetically, KG1a cells harbor the chromosome 7 deletion. In our experiments, KG1a cells were cultured in RPMI 1640 media supplemented with 10\% fetal bovine serum. Both K562-Luc and KG1a cells were grown in a humidified chamber with $5 \% \mathrm{CO}_{2}$ and $95 \%$ humidity at $37^{\circ} \mathrm{C}$.

fb-PMT, (fluorobenzyl Polyethylene glycol Mono-Triazole tetraiodothyroacetic acid), was synthesized at our facility (Pharmaceutical Research Institute, Rensselaer, NY, USA) and GMP scaleup was done at Dalton Pharmaceuticals (Toronto, Canada) [7, 16]. fb-PMT (molecular weight 2478.9 daltons) is a white powder that is soluble in Tris buffer at $\mathrm{pH} 8.0, \sim 100 \mathrm{mg} / \mathrm{mL}$, with a final pH of 7.4.

\section{Competitive Binding of fb-PMT to Purified av $\beta 3$}

The binding affinity of fb-PMT to purified av $\beta 3$ was assessed using a previously described methods $[7,20]$. Purified av $\beta 3(1 \mu \mathrm{g} / \mathrm{mL})$ was coated to polystyrene microtiter plate wells at $4^{\circ} \mathrm{C}$ overnight, and then the wells were blocked with $3 \%$ bovine serum albumin (BSA) for 2 $\mathrm{h}$ at room temperature. The wells were washed with buffer $\mathrm{A}(50 \mathrm{mM}$ tris/ $\mathrm{HCl}, 100 \mathrm{mM} \mathrm{NaCl}, 1 \mathrm{mM} \mathrm{CaCl} 2,1 \mathrm{mM} \mathrm{MgCl} 2,1 \% \mathrm{BSA})$, and anti-av $\beta 3$ conjugated with biotin (1:1000 in buffer $\mathrm{A}$ ) was added and incubated for $1 \mathrm{~h}$ at room temperature. Increasing concentrations of compounds were added in the presence or absence of fibrinogen and incubated for $2 \mathrm{~h}$ at room temperature, and then wells were washed three times with buffer $A$ and incubated with a streptavidin - Horseradish peroxidase (HRP) conjugate (1:1000 in buffer A) for 1 $\mathrm{h}$ at room temperature. Finally, wells were washed three times with buffer $\mathrm{A}$, and $100 \mu \mathrm{L}$ peroxidase substrate $3,3^{\prime}, 5,5^{\prime}-$ tetramethylbenzidine (TMB) was added, and the reaction was terminated after 30 min with $50 \mu \mathrm{L}$ of $450 \mathrm{~nm}$ stop solution for TMB. Absorbance was determined at $450 \mathrm{~nm}$ with a plate reader.

\section{Animals and treatment protocols}

Mice were used in accordance with Public Health Service Policy on Humane Care and Use of Laboratory Animals and approved by the Albany VA Medical Center (Albany, NY, USA) institutional animal care and use committee (IACUC) (protocol number 545017). Eighty male NSG-S mice (6-8 weeks of age) were purchased from Jackson Laboratories (Bar Harbor, ME). Preconditioning was done by intraperitoneal injection of busulfan ( $30 \mathrm{mg} / \mathrm{kg}$, Otsuka America Pharmaceutical Inc., Hayward, CA, USA) 24 hours prior to cell injections. K562-Luc cells and primary AML cells (6373) (5 to10 × $10^{6}$ per mouse) were transplanted via tail vein injection into mice.

For the K562-Luc animal model (40 mice), in vivo imaging system (IVIS) (Perkinelmer, Waltham, MA, USA) scans and the peripheral blood smears examination were performed on animals once a week. The fb-PMT treatment schedule was initiated on day 10 postimplantation when increased counts of blast cells became evident in peripheral blood smears and confirmed by IVIS signals. fb-PMT was administered subcutaneously (s.c.) daily at 3 different doses $(1,3$, and $10 \mathrm{mg} / \mathrm{kg}$ body weight) or vehicle, PBS (control) for 21 days for both the ON arm (21 days treatment and then 20 mice have been sacrificed) and the ON + OFF arm ( 21 days treatment followed by 14 days treatment discontinuation and then the remaining 20 mice have been sacrificed). Control animals were administered with vehicle (phosphate buffered saline (PBS), pH 7.4) daily.

In experiments using the primary AML cell animal model (40 mice), the treatment protocol was initiated on animals after confirmation of successful engraftment. Treatment was initiated on day 40 post-implantation with fb-PMT $(1,3$, and $10 \mathrm{mg} / \mathrm{kg}$ ) or control (vehicle, PBS) daily s.c. for 28 days. Twenty animals (ON arm) were humanely sacrificed after 28 days of treatment, and peripheral blood smears 
and bone marrow aspirates were examined histologically at the end of the 28 days of treatment. To evaluate the relapse after treatment, the remaining 20 mice (ON + OFF arm) were maintained without treatment for an additional 14 days, then they were humanely sacrificed and processed to obtain samples of peripheral blood smears, bone marrow aspirates and organs for histological examination. The maintaining for 14 days (ON + OFF) was established based on the animals' condition in the control groups.

\section{Assessment of Leukemic cells engraftment by flow cytometry and immunohistostaining}

Human AML engraftment was assessed by flowcytometry and defined as the percentage of human CD45+/CD33 + cells in total live mononuclear cells. Fresh bone marrow cells from NSG-S mice engrafted with K562-Luc and primary AML cells (6373) were collected at day 10 and 40 post-engraftment, respectively, once the blast cells detected in peripheral blood smear. samples were stained with antibodies for cell surface markers: anti- human CD45-PE, anti-human CD33-FITC (BD Biosciences, San Jose, CA, USA). Cells were incubated with monoclonal antibodies for $15 \mathrm{~min}$ at room temperature, washed once in PBS containing $0.1 \%$ human serum albumin (HSA), and analyzed by flow cytometry. Data acquisition was performed using a FACS Aria III (BD Biosciences) equipped with an argon and red diode laser, and analysis was performed using Cell Quest software (BD Biosciences).

As the K562-Luc cells express dim CD34, immunohistochemistry was performed for Formalin-fixed decalcified femurs from primary AML cells (6373) transplanted mice were paraffin-embedded and sectioned at $5 \mu \mathrm{m}$ sections. Slides were stained using human antiCD34 primary antibody (R\&D system, Minneapolis, MN USA) then with HRP conjugated secondary antibody (Cell Signaling Technology Inc. Danvers, MA, USA). HRP activity was detected by diaminobenzidine tetrahydrochloride (DAB) and the slide were counterstain by Methyl green.

\section{Safety study in animal models}

The objective of this study was to evaluate the safety of fb-PMT after a period of daily s.c injections for 28 days in multiple species. Thirty-two cynomolgus monkeys (CM) were administered fb-PMT (2.5, 7.5 and $15 \mathrm{mg} / \mathrm{kg}$ ) or vehicle daily s.c for 28 days (8 CM/ group). Clinical chemistry, biomarkers and histopathological examination were carried out (data not shown).

\section{RNA isolation from AML cells and microarrays}

K562-Luc and KG1a cells were cultured in $50 \mathrm{~cm}^{2}$ cell culture flasks with $10 \mathrm{~mL}$ phenol red free RPMI media containing $10 \%$ FCS to $75 \%$ confluence. K562-Luc and KG1a cells were treated (at 50\% confluence) with $30 \mu \mathrm{M}$ fb-PMT for 48 hours. Total RNA was immediately isolated from harvested cells using Trizol and checked for quality using an Agilent Bioanalyzer (Agilent Technologies, Santa Clara, CA) before being used for microarray analysis. The quality and the concentrations of the extracted RNA were analyzed using a NanoDrop (Thermo Fisher Scientific, Waltham, MA) and the Agilent Bioanalyzer. RNA samples (100 ng) deemed to be of sufficient quality (RIN greater than 8) were processed according to the standard Affymetrix RNA labeling protocol. At least two independent biological replicates of control and treated samples were concurrently interrogated in microarray analyses. In preliminary experiments, the treatment dose and duration were carefully selected so as to not significantly affect growth and survival of target cells for the duration of experiments.

Microarray Analysis. Labeled RNA samples were processed for hybridization employing the Clariom ${ }^{\text {TM }} \mathrm{S}$ human array platform (Affymetrix, Santa Clara, CA) at the Center for Functional Genomics, University at Albany, Rensselaer, NY. Briefly, 100 ng of total RNA was processed using the WT Plus Reagent kit (Affymetrix). Sense target Complementary DNA (cDNAs) were generated using the standard Affymetrix WT protocol and hybridized to Affymetrix Human Clariom S arrays. Arrays were washed, stained, and scanned on a GeneChip 3000 7G scanner using Affymetrix GeneChip Command Console Software (AGCC). Transcriptome Analysis Console Software (TAC v3.0.1.5) was used to identify differentially expressed genes (DEGs). Briefly, the CEL files were summarized using the SST-RMA algorithm in TAC and the normalized data were subjected to one-way ANOVA with a Benjamin Hochberg False Discovery Rate correction included $(P<0.05)$. A 1.5 -fold expression change cut-off was used to select entities that were statistically differentially expressed between the conditions being compared (treated and untreated groups). In the standard workflow protocol, the fragmented biotinlabeled cDNAs were hybridized for $16 \mathrm{~h}$ to Affymetrix Arrays, scanned on an Affymetrix Scanner $30007 \mathrm{G}$ using AGCC software, and processed as described above. Alternatively, CEL files after QC screening using Affymetrix Expression Console software were imported into GeneSpring GX11.5 (Agilent Technologies). The data was then quantile normalized using PLIER and baseline transformed to the median of the control samples. The probe sets were further filtered to exclude the bottom 20th percentile across all samples. The resulting entity lists were subjected to an unpaired T-test with the Benjamini-Hochberg False Discovery rate correction and a 1.5-fold 
expression changes filter to identify differentially expressed transcripts between the control and test conditions at a p-value $<0.05$. All analyzed and reported data are MIAME compliant and the raw data have been deposited in Gene Expression Omnibus (GEO; GSE95790) as detailed on the Microarray Gene Expression Data Society (MGED) website (http://www.mged.org/Workgroups/MIAME/miame.html). Overall, the workflow of the microarray analyses was modeled based on previously published contributions [21].

Gene set enrichment analyses of DEGs were done using the Enrichr bioinformatics platform, which enables the interrogation of nearly 200,000 gene sets from more than 100 gene set libraries. The Enrichr API (January 2018 through October 2020 releases) [22, 23] was used to test genes of interest for significant enrichment in numerous functional categories. When technically and analytically feasible, different sets of DEGs defined at multiple significance levels of statistical metrics and comprising from dozens to several thousand individual genetic loci were analyzed using differential Gene set enrichment analysis (GSEA) to gain insights into biological effects of DEGs and infer potential mechanisms of anticancer activities. This approach was successfully implemented for identification and characterization of human-specific regulatory networks governed by human-specific transcription factor-binding sites [24] and functional enhancer element [25], 13,824 genes associated with 59,732 human-specific regulatory sequences [26], 8,405 genes associated with 35,074 human-specific neuroregulatory single-nucleotide changes [27]. Initial GSEA entail interrogations of each specific set of DEGs using 29 distinct genomic databases, including comprehensive pathway enrichment Gene Ontology (GO) analyses followed by in-depth analyses of the selected genomic databases deemed most statistically informative. In all tables and plots (unless stated otherwise), in addition to the nominal $p$ values and adjusted $p$ values, the "combined score" calculated by Enrichr software is reported, which is a product of the significance estimate and the magnitude of enrichment (combined score $c=\log (p) * z$, where $p$ is the Fisher's exact test $\mathrm{p}$-value and $\mathrm{z}$ is the $\mathrm{z}$-score deviation from the expected rank).

\section{Statistical analysis}

An overall comparison of the means for all groups was carried out using a one-way ANOVA. Tukey confidence intervals were used to test for differences in means for each experimental group versus the control group. Results are presented as means \pm S.D. A value of $P<$ 0.05 indicated a statistically significant difference.

\section{Results}

In Vitro Binding Affinity of fb-PMT with the thyrointegrin av $\beta 3$.

In binding affinity experiments of fb-PMT, we confirmed that fb-PMT has a high affinity for the thyrointegrin av $\beta 3$ receptors with a lower $\mathrm{IC}_{50}$ (50\% inhibitory concentration) of $0.23 \mathrm{nM}$ (Fig. 1).

Preclinical in vivo therapy experiments revealed potent fb-PMT anticancer activities.

Effects of fb-PMT therapy on K562-Luc human leukemic cell line FLT3-ITD primary human AML cells engrafted in transgenic mice.

In the K562-Luc engrafted in transgenic mice, blast cells appeared in the blood smears of NSG-S mice 10 days after engraftment, with an average value of $40 \%$. After 21 days of fb-PMT daily s.c. injection, blast cell counts continually and consistently decreased in a dosedependent manner in treated versus control groups, while animals in the control group showed increased blast cells in the peripheral blood. No blast cells could be detected in fb-PMT-treated animals $(10 \mathrm{mg} / \mathrm{kg})$ at the end of the treatment. Furthermore, there was no rebound increase in peripheral blast cells at 1 and $3 \mathrm{mg} / \mathrm{kg}$ with full sustained remission at fb-PMT dose of $10 \mathrm{mg} / \mathrm{kg}$ at $1-2$ weeks post-discontinuation of treatment (Fig. 2, Supplementary Figure S1A).

On the other hand, primary AML cells (6373-FLT3-ITD) cells appeared in the blood smears of NSG-S mice 40 days after engraftment, with an average value of $26 \%$. After 28 days of daily s.c. treatment, peripheral smears of treated animals were entirely normal at fb-PMT dose of $10 \mathrm{mg} / \mathrm{kg}$. Daily s.c. injections of fb-PMT at 1,3, and $10 \mathrm{mg} / \mathrm{kg}$ doses prevented blast cell expression/reproduction compared to controls by $54 \%, 75 \%$, and $90.5 \%$, respectively (Fig. 2 and Supplemental Figure S1B).

After termination, the bone marrow K562-Luc engrafted mice with a daily treatment of fb-PMT at $3 \mathrm{mg} / \mathrm{kg}$ manifested 30-40\% infiltration with blast cells, while $70 \%$ maturation could be detected. fb-PMT-treated animals at $10 \mathrm{mg} / \mathrm{kg}$ dose presented bone marrows with blast cell counts $<5 \%$ and $>95 \%$, normal maturation have been documented (segmented neutrophils). The remission was maintained in all treated mice at least 2 weeks after fb-PMT therapy discontinuation (Fig. 3A, 3B and Supplemental Figure S2A). 
IVIS scans and histopathological results at sacrifice showed a dose-dependent decrease of brain, lung, liver, and spleen infiltration with the leukemic cells in the group of fb-PMT-treated mice $(10 \mathrm{mg} / \mathrm{kg})$ in comparison to control group Supplemental Figure S3. The fb-PMT therapy at $10 \mathrm{mg} / \mathrm{kg}$ dose in the ON + OFF treatment group resulted in successfully maintained remission in all animals 2 weeks after withdrawal of the daily treatment. The sustained remission was confirmed using blood smear analyses, IVIS scans, flowcytometry and histopathological examinations.

Regarding the bone marrow samples from mice engrafted with primary AML cells (FLT3-ITD), the fb-PMT-treated group (10 mg/kg) restored the normal bone marrow maturation with abundant megakaryocytes in comparison to control animals (Fig. 3C and 3D). The results were confirmed with flowcytometry and immunohistochemistry analysis (Supplemental Figure S2)

Furthermore, we evaluated the splenic infiltration in our animal models. Histopathological results showed a marked decrease of splenic metastases of the leukemic cells in the group treated with fb-PMT $(10 \mathrm{mg} / \mathrm{kg})$ compared to control group (Fig. 4). Similarly, to the K562Luc AML experiments, the primary AML model (ON + OFF) group $(10 \mathrm{mg} / \mathrm{kg})$ manifested the successful maintenance of remission 2 weeks after withdrawal of daily therapy. The splenic weight showed marked decrease (80\%) even with the low dose (1 mg/kg). The ON + OFF groups maintained normal splenic weight in comparison to control, which may reflect successful prevention of engraftment (Fig. 4A). Treatment with fb-PMT daily for 28 days (ON treatment) or 28 days ON and 14 days off treatment (ON + OFF treatment) resulted in maximal suppression of primary AML infiltration into the spleen of AML engrafted transgenic mice (Fig. 4B).

\section{Microarray analyses of fb-PMT effects on gene expression in human AML cells}

Previous contributions have established that one of the principal molecular mechanisms of anticancer activities of thyrointegrin av $\beta 3$ antagonists is exemplified by significant changes in expression of genes essential for growth and survival of malignant cells [28-32]. Therefore, to gain insights into mechanisms of the fb-PMT activities against cancer cells, it was of interest to do genome-wide gene expression profiling experiments. Following 2 days of a single-dose treatment with $30 \mu \mathrm{M}$ of fb-PMT, RNA samples were extracted from biological replicates of control and treated human AML cells and subjected to microarray analyses (Methods). Results of these analyses are reported in Figs. 5-7 and Tables 1-3. 
Table 1

Examples of mimicry of pathway activation and pathway interference gene expression signatures (GES) identified in fb-PMT-treated K562 cells.

\begin{tabular}{|c|c|c|c|c|}
\hline $\begin{array}{l}\text { fb-PMT } \\
\text { pathway } \\
\text { activation } \\
\text { GES }\end{array}$ & Genes & P-value* & $\begin{array}{l}\text { Odds } \\
\text { Ratio* }\end{array}$ & $\begin{array}{l}\text { Combined } \\
\text { Score* }\end{array}$ \\
\hline $\begin{array}{l}\text { RB1 } \\
\text { pathway } \\
\text { signature } \\
(n=10)\end{array}$ & STARD4;TMEM2;SESN3;SPIN4;SLX4IP;CD109;CENPE;CEP135;TCP11L2;PLD1 & 3.70E-04 & 6.266319 & 49.51741 \\
\hline $\begin{array}{l}\text { IRF9 } \\
\text { pathway } \\
\text { signature } \\
(n=6)\end{array}$ & CENPE;EID3;SESN3;CD109;ASB7;TCP11L2 & $5.12 \mathrm{E}-04$ & 7.54717 & 57.18613 \\
\hline $\begin{array}{l}\text { MAML1 } \\
\text { pathway } \\
\text { signature } \\
(n=6)\end{array}$ & CENPE;PTAR1;STARD4;TMEM30A;CD109;TCP11L2 & 0.001655 & 4.696673 & 30.07697 \\
\hline $\begin{array}{l}\text { RAP1A } \\
\text { pathway } \\
\text { signature } \\
(n=5)\end{array}$ & CENPE;SPIN4;ACSL1;ELOVL7;IL18R1 & 0.001067 & 6.410256 & 43.86473 \\
\hline $\begin{array}{l}\text { GATA4 } \\
\text { pathway } \\
\text { signature } \\
(n=5)\end{array}$ & ERRFI1;ACSL1;LRRC28;CD9;ELOVL7 & 4.15E-04 & 7.905138 & 61.56706 \\
\hline $\begin{array}{l}\text { fb-PMT } \\
\text { pathway } \\
\text { interference } \\
\text { GES }\end{array}$ & Genes & P-value* & $\begin{array}{l}\text { Odds } \\
\text { Ratio* }\end{array}$ & $\begin{array}{l}\text { Combined } \\
\text { Score* }\end{array}$ \\
\hline $\begin{array}{l}\text { MYC } \\
\text { pathway } \\
\text { signature } \\
(n=8)\end{array}$ & ERRFI1;CENPE;BLOC1S6;TMEM30A;CD109;SESN3;ZNF17;KDSR & 2.04E-04 & 9.21659 & 78.29477 \\
\hline $\begin{array}{l}\text { HIF1A } \\
\text { pathway } \\
\text { signature } \\
(n=6)\end{array}$ & ERRFI1;ERV3-1;TCP11L2;SH3BGRL2;ELOVL7;IL18R1 & $1.48 \mathrm{E}-04$ & 7.430341 & 65.52441 \\
\hline $\begin{array}{l}\text { TWIST1 } \\
\text { pathway } \\
\text { signature } \\
(n-5)\end{array}$ & EID3;SESN3;CD109;TCP11L2;ASB7 & 0.00152 & 5.91716 & 38.39501 \\
\hline $\begin{array}{l}\text { TFAP2C } \\
\text { pathway } \\
\text { signature } \\
(n=5)\end{array}$ & CENPE;SPIN4;ACSL1;CD109;ELOVL7 & $5.21 \mathrm{E}-04$ & 7.518797 & 56.84253 \\
\hline
\end{tabular}


Table 2

Mimicry of pathway activation and pathway interference gene expression signatures (GES) identified in fb-PMT-treated K562 cells.

\begin{tabular}{|c|c|c|c|c|c|}
\hline Enriched Terms & $\begin{array}{l}\text { P. } \\
\text { value* }\end{array}$ & $\begin{array}{l}\text { Adjusted P- } \\
\text { value* }\end{array}$ & $\begin{array}{l}\text { Odds } \\
\text { Ratio* }\end{array}$ & $\begin{array}{l}\text { Combined } \\
\text { Score* }\end{array}$ & Genes \\
\hline $\begin{array}{l}\text { IRF9 OE HUMAN GSE50002 CREEDSID } \\
\text { GENE } 1659 \text { DOWN }\end{array}$ & $\begin{array}{l}2.89 E- \\
07\end{array}$ & $5.65 \mathrm{E}-04$ & 31.44654 & 473.5 & CENPE;EID3;SESN3;CD109;ASB7 \\
\hline $\begin{array}{l}\text { TFAP2C SIRNA HUMAN GSE15481 } \\
\text { CREEDSID GENE } 2895 \text { DOWN }\end{array}$ & $\begin{array}{l}2.94 \mathrm{E}- \\
07\end{array}$ & $2.88 \mathrm{E}-04$ & 31.32832 & 471.2 & CENPE;ACSL 1;SPIN4;CD109;ELOVL7 \\
\hline $\begin{array}{l}\text { TFAP2C KD HUMAN GSE15481 } \\
\text { CREEDSID GENE } 2970 \text { DOWN }\end{array}$ & $\begin{array}{l}3.60 \mathrm{E}- \\
07\end{array}$ & 2.35E-04 & 30.08424 & 446.4 & CENPE;ACSL 1;SPIN4;CD109;ELOVL7 \\
\hline $\begin{array}{l}\text { TWIST } 1 \text { OE MOUSE GSE50002 } \\
\text { CREEDSID GENE } 1075 \text { UP }\end{array}$ & $\begin{array}{l}9.62 \mathrm{E}- \\
07\end{array}$ & 4.71E-04 & 24.65483 & 341.6 & EID3;SESN3;CD109;ASB7;TCP11L2 \\
\hline $\begin{array}{l}\text { IRF9 OE HUMAN GSE50002 CREEDSID } \\
\text { GENE } 1663 \text { DOWN }\end{array}$ & $\begin{array}{l}1.16 \mathrm{E}- \\
06\end{array}$ & 4.54E-04 & 23.74169 & 324.5 & EID3;SESN3;CD109;ASB7;TCP11L2 \\
\hline $\begin{array}{l}\text { MYC OE U2OS HUMAN GSE59819 } \\
\text { RNASEQ UP }\end{array}$ & $\begin{array}{l}6.23 E- \\
06\end{array}$ & 0.002034 & 30.72197 & 368.2 & CENPE;ERRFI1;TMEM30A;CD109 \\
\hline $\begin{array}{l}\text { MYC OE U2OS HUMAN GSE6 } 6789 \\
\text { RNASEQ UP }\end{array}$ & $\begin{array}{l}6.23 E- \\
06\end{array}$ & 0.001743 & 30.72197 & 368.2 & CENPE;ERRFI1;TMEM30A;CD109 \\
\hline $\begin{array}{l}\text { IRF9 OE HUMAN GSE50002 CREEDSID } \\
\text { GENE } 1656 \text { DOWN }\end{array}$ & $\begin{array}{l}8.26 \mathrm{E}- \\
06\end{array}$ & 0.002021 & 28.6123 & 334.9 & SESN3;CD109;ASB7;TCP11L2 \\
\hline $\begin{array}{l}\text { IRF9 OE HUMAN GSE50002 CREEDSID } \\
\text { GENE } 1653 \text { DOWN }\end{array}$ & $\begin{array}{l}1.43 E- \\
05\end{array}$ & 0.00312 & 24.87562 & 277.4 & SESN3;CD109;ASB7;TCP11L2 \\
\hline $\begin{array}{l}\text { IRF9 OE HUMAN GSE50002 CREEDSID } \\
\text { GENE } 1657 \text { DOWN }\end{array}$ & $\begin{array}{l}2.20 \mathrm{E}- \\
05\end{array}$ & 0.004317 & 22.29654 & 239.1 & SESN3;CD109;ASB7;TCP11L2 \\
\hline $\begin{array}{l}\text { IRF9 OE HUMAN GSE50002 CREEDSID } \\
\text { GENE } 1654 \text { DOWN }\end{array}$ & $\begin{array}{l}2.45 \mathrm{E}- \\
05\end{array}$ & 0.004353 & 21.71553 & 230.6 & SESN3;CD109;ASB7;TCP11L2 \\
\hline $\begin{array}{l}\text { HIF1A KO MOUSE GSE35111 } \\
\text { CREEDSID GENE } 1406 \text { DOWN }\end{array}$ & $\begin{array}{l}2.98 \mathrm{E}- \\
05\end{array}$ & 0.004868 & 20.63983 & 215.1 & ERRFI1;TCP11L2;ELOVL 7;IL $18 R 1$ \\
\hline
\end{tabular}


Table 3

Examples of functionally-significant genes down-regulated by the fb-PMT treatment in KG1A human AML cells.

\begin{tabular}{|llll|}
\hline Description & Gene Symbol & Fold Change & P-value \\
\hline X-linked inhibitor of apoptosis, E3 ubiquitin protein ligase & XIAP & -2.9 & 0.0185 \\
\hline osteoclast stimulating factor 1 & OSTF1 & -2.86 & 0.0331 \\
\hline signal transducer and activator of transcription 2 & STAT2 & -2.81 & 0.0202 \\
\hline thymopoietin & TMPO & -2.59 & 0.0069 \\
\hline signal transducer and activator of transcription 4 & STAT4 & -2.54 & 0.0451 \\
\hline YES proto-oncogene 1, Src family tyrosine kinase & YES1 & -2.49 & 0.0315 \\
\hline polymerase (RNA) II (DNA directed) polypeptide B, 140kDa & POLR2B & -2.44 & 0.0354 \\
\hline cyclin-dependent kinase 14 & CDK14 & -2.21 & 0.0402 \\
\hline TTK protein kinase & TTK & -2.2 & 0.046 \\
\hline topoisomerase (DNA) III alpha & TOP3A & -2.12 & 0.0116 \\
\hline prohibitin 2; small Cajal body-specific RNA 12 & PHB2 & -2.03 & 0.042 \\
\hline cyclin-dependent kinase 17 & CDK17 & -1.97 & 0.0303 \\
\hline phosphoglycerate kinase 2 & PGK2 & -1.85 & 0.0471 \\
\hline polymerase (DNA directed), epsilon 2, accessory subunit & POLE2 & -1.83 & 0.0441 \\
\hline B-Raf proto-oncogene, serine/threonine kinase & BRAF & -1.81 & 0.0315 \\
\hline growth factor receptor bound protein 2 & GRB2 & -1.81 & 0.0301 \\
\hline Pim-1 proto-oncogene, serine/threonine kinase & PIM1 & -1.71 & 0.038 \\
\hline serine/threonine kinase 4 & STK4 & -1.69 & 0.0135 \\
\hline prostaglandin E synthase 3 (cytosolic) & PTGES3 & -1.56 & 0.0429 \\
\hline B-cell CLL/lymphoma 9 & BCL9 & -1.52 & 0.0334 \\
\hline
\end{tabular}

Overall, there were 518 significantly down-regulated gene expression records and 283 significantly up-regulated gene expression records, expression of which were changed at least 1.5-fold in fb-PMT-treated K562 cells. In fb-PMT-treated KG1a cells, 223 significantly down-regulated gene expression records and 191 significantly up-regulated gene expression records were identified, expression of which were changed at least 1.5-fold in fb-PMT-treated cells. All DEG identified by the Affymetrix Expression Console software were subjected to GSEA employing a panel of 29 genomic databases (Methods). Analyses of fb-PMT treatment-induced DEGs in both K562 and KG1a cells identified sets of down-regulated genes and a genomic database of Transcription Factor (TF) Perturbations Followed by Expression as the most informative setting among comparison records. GSEA of down-regulated DEGs using the TF Perturbations Followed by Expression database identified 60 and 84 significantly enriched records (adjusted p value < 0.05 ) for fb-PMT-treated K562 and KG1a cells, respectively.

GSEA of fb-PMT effects on gene expression revealed signatures of the molecular mimicry of both activation of and interference with multiple transcriptional pathways:

Follow-up analyses of down-regulated DEGs using the TF Perturbations Followed by Expression database identified multiple examples of the molecular mimicry of pathway activation and pathway interference gene expression signatures (GES) identified in fb-PMT-treated human AML cells (Table 1; Fig. 5). Notable examples of the fb-PMT-induced GES of transcriptional pathway's activation include RB1, IRF9, MAML1, RAP1A, and GATA4 pathways, and examples of the fb-PMT-induced GES of pathway's interference include MYC, HIF1A, TWIST1, and TFAP2C pathways. Integrations of DEGs comprising fb-PMT-induced GES listed in Table 1 identified a total of 25 genes, differential expression of which appears to define molecular signals of either activation of or interference with transcriptional pathways 
in fb-PMT-treated human AML cells (Fig. 5). GSEA of genes comprising the 25-gene and 12-gene expression signatures validated their significance in defining observations of the molecular mimicry of transcriptional pathways' activation and interference induced by fbPMT treatment in human AML cells (Figs. 5-7, Table 2). GSEA of all significant DEGs confirmed and extended these findings.

Interestingly, GSEA identified the SNA/transcriptional pathway as the most significantly enriched pathway of the molecular interference observed in K562 cells treated with fb-PMT among either down-regulated or up-regulated DEGs (Supplemental Fig. 4). Additional examples of the specific genes and pathways of potential functional significance revealed by the GSEA of 233 genes down-regulated in KG1a cells after fb-PMT treatment are shown in Table 3. Of note, GSEA of the LINCS L1000 Ligand Perturbations database of upregulated genes revealed evidence of molecular interference with functions of multiple growth factors in human cancer cell lines (Fig. 7).

GSEA of fb-PMT effects on gene expression revealed signatures of the molecular interference with a regulatory crosstalk of estrogen pathway and multi-kinase transcriptional matrix of cell cycle progression.

GSEA of databases of Ligand perturbations from GEO focused on up-regulated genes and Ligand perturbations from GEO focused on down-regulated genes revealed multiple examples of molecular interference with transcriptional signaling induced by many endogenous ligands, among which the enrichment of genes implicated in estrogen signaling was particularly apparent (Fig. 6 and Supplemental Fig. 4). Similarly, GSEA of the ARCHS4 Kinases Co-expression database revealed evidence of the molecular interference with functions of multiple kinases. GSEA of the integrated 69-gene signature of the fb-PMT interference with estrogen signaling in human AML cells identified 16 genes that appear implicated in transcriptional regulatory crosstalk of estrogens with multiple kinases in human tissues (Supplemental Fig. 5). Integration of 16 estrogen-regulated genes with 35 genes encoding kinases engaged in regulatory crosstalk in human tissues generated the 50-gene signature of estrogen pathway/multi-kinase gene expression regulatory matrix, which appears engaged in the cell cycle progression pathway (Supplemental Fig. 5). Intriguingly, GSEA of the 50-gene interference signature with estrogen-kinase regulatory matrix using the DisGeNET database of human disorders revealed that these genes were implicated in a remarkably broad spectrum of human malignancies (Supplemental Fig. 5),

\section{Discussion}

The present study assessed the efficacy of a novel thyrointegrin av $\beta 3$ antagonist (fb-PMT) against human AML cells. fb-PMT proved to be a highly effective anticancer agent in vivo. Experiments using different human AML models in mice documented eradication of the leukemic cells' engraftment after 3-4 weeks of continuous treatment with fb-PMT. Experimental therapy ON + OFF studies showed the significant efficacy of fb-PMT in preventing relapse, thus confirming the curative effects in vivo of fb-PMT treatment in clinically relevant animal models of human AML. The role of integrin in leukemogenesis was indicating by Yi et al. who reported that binding of leukemia cells to the bone marrow extracellular matrix (ECM) through integrins might influence drug response and the survival of leukemic cells [9]. Integrin aV $\beta 3$ has been reported to be more expressed in AML cells especially CD34-positive cells, monocytic leukemias, patient with NPM, FLT3-ITD [12].

Consistent with the previous reports on mechanisms of anticancer actions of thyrointegrin av $\beta 3$ antagonists [29, 33-37], genome-wide microarray screens reported here demonstrated that fb-PMT appears to exert its potent anticancer actions on human AML cells through the molecular interference mechanism with multiple signaling pathways supporting growth and survival of leukemic cells. We detected significant molecular signals of transcriptional interference with gene expression induced in human cancer cells in response to multiple growth factors such as EGF, IGF-1, TGFA, and many others.

Other significant examples of the fb-PMT-induced GES of pathway's interference include SNAI MYC HIF1A, TWIST1, and TFAP2C. Notably, inference of potential contribution to the fb-PMT anticancer activity of the interference with these pathways seems highly congruent with their known biological functions such as cell cycle control (MYC), survival and maintenance of stem cells (HIF1A, TFAP2C), and essential features of the malignant phenotype (TWIST1, SNAI) [38-52].

Consistently, examples of the fb-PMT-induced GES of transcriptional pathway's activation include RB1, IRF9, MAML1, RAP1A, and GATA4 pathways, known biological functions of which appear highly consistent with the hypothesis that activation of these pathways may contribute to fb-PMT anticancer activity [53-56].

Finally, consistent with our previous reports on the crosstalk between integrin av $\beta 3$ and estrogen receptor a $(E R a)$, which contributes to the induced proliferation of cancer cells [57-60], we found that fb-PMT interfered with estrogen signaling in human AML cells. The av $\beta 3$

Page $10 / 22$ 
agonist (thyroid hormone) was associated with increased phosphorylation and nuclear enrichment of ERa. Confocal microscopy indicated that both T4 and estradiol (E2) caused nuclear translocation of integrin av and phosphorylation of ERa. The specific ERa antagonist (ICl 182,780; fulvestrant) blocked T4-induced ERK1/2 activation, ERa phosphorylation, PCNA expression, and proliferation [57].

Furthermore, GLP toxicity study showed that fb-PMT is safe and well tolerated at $>60$ fold higher than the effective anticancer doses after daily s.c injection for 4 weeks in rat and monkey models (data not shown).

fb-PMT is an effective anticancer agent against solid tumors and hematological malignancies, with broad spectrum, potent antiangiogenic activity against all known growth factors and other pro-angiogenesis stimuli $[28,61,62]$. Collectively, preclinical findings of $\mathrm{fb}-\mathrm{PMT}$ warrant its clinical investigation for the effective and safe management of AML.

\section{Conclusion}

Our novel thyrointegrin av $\beta 3$ antagonist, fb-PMT, is preferable for potential clinical use because of its efficacy against human xenograft models of AML as well as its safety, even at high doses. Our genomic data demonstrated the potent anticancer actions on human AML through the molecular interference mechanism with multiple signaling pathways supporting growth and survival of leukemic cells. fbPMT could have a broader application because it could be utilized, either alone or in combination with chemotherapeutic agents, to treat AML cancer or other cancers.

\section{Abbreviations}

AGCC: Affymetrix GeneChip Command Console Software

AML: Acute myeloid leukemia

Akt: Protein kinase B

BCR-ABL: Breakpoint cluster region gene/ Abelson proto-oncogene

BSA: Bovine serum Albumin

CEBPA: CAAT enhancer-binding protein alpha.

DEGs: Differentially expressed genes

ECM: Extracellular matrix

Era: Estrogen receptor a

fb-PMT: fluorobenzyl Polyethylene glycol conjucated tetraiodothyroacetic acid

FBS: Fetal bovine serum

RPMI: Roswell Park Memorial Institute Medium

FLT3-ITD: FMS-like tyrosine kinase-3-internal tandem duplication

GEO: Gene Expression Omnibus

cDNA: Complementary DNA

PBS: Phosphate-buffered saline

HRP: Horseradish peroxidase

GES: Gene expression signatures

GSEA: Gene set enrichment analysis 
HIF1A: Hypoxia Inducible Factor 1 Subunit Alpha

HSA: Human serum albumin

IACUC: Institutional animal care and use committee

IDH1/2: Isocitrate dehydrogenases 1 and 2

IRF9: Interferon Regulatory Factor 9

IVIS: In Vivo Imaging Systems

MAML1: Mastermind Like Transcriptional Coactivator 1

MGED: Microarray Gene Expression Data

NPM: Nucleophosmin

RAP1A: Ras-related protein Rap-1A

RB1: Retinoblastoma protein-1

RGD: Arginine-glycine-aspartate

S.C.: Subcutaneously

SNA1: Snail Family Transcriptional Repressor 1

TF: Transcription Factor

TFAP2C: Transcription Factor AP-2 Gamma

TMB: Tetramethylbenzidine

TP53: Tumor protein p53

TWIST1: Twist Family BHLH Transcription Factor 1

\section{Declarations}

\section{Ethics approval and consent to participate}

Primary human AML cells (De novo AML 6373, harboring FLT3-ITD mutation) were collected by leukapheresis from AML patients at the University Hospital, University of Pennsylvania, with informed consents (IRB protocol 703185).

Mice were used in accordance with Public Health Service Policy on Humane Care and Use of Laboratory Animals and approved by the Albany VA Medical Center (Albany, NY, USA) IACUC (protocol number 545017).

\section{Consent for publication}

"Not applicable"

\section{Availability of data and materials}

All data generated or analysed during this study are included in this published article and its supplementary information files. For further inquiries regarding the current study data, the corresponding author can provide any required explanations on reasonable request.

\section{Competing interests}

S.A. Mousa holds several patents on anticancer compounds assigned to NanoPharmaceuticals LLC and founder of the company. G.V. Glinsky is a paid consultant to NanoPharmaceuticals LLC. The remaining authors have no conflicts to declare.

Page $12 / 22$ 
Funding

not applicable (No fund received)

Author Contributions

S.A Mousa designed the experiment and is the Principal Investigator. Noureldien Darwish and Sudha Thangirala conducted the experiment. Noureldien Darwish did the data analysis. G.V. Glinsky contributed to the genetic analysis. Noureldien Darwish contributed to the manuscript write up and data interpretation. All authors have approved the final version of the manuscript.

Acknowledgment

We appreciate Dr. Kelly A. Keating, Pharmaceutical Research Institute, for her excellent editing of this manuscript. Special thanks to Dr. Sridar V. Chittur, Center for Functional Genomics, SUNY Albany, for the processing microarray samples.

\section{References}

1. Key Statistics for Acute Myeloid Leukemia (AML) [https://www.cancer.org/cancer/acute-myeloid-leukemia/about/keystatistics.html]

2. Döhner H, Weisdorf DJ, Bloomfield CD: Acute Myeloid Leukemia. New England Journal of Medicine 2015, 373(12):1136-1152.

3. Yu J, Jiang PYZ, Sun H, Zhang X, Jiang Z, Li Y, Song Y: Advances in targeted therapy for acute myeloid leukemia. Biomarker Research 2020, 8(1):17.

4. Ciciarello M, Corradi G, Loscocco F, Visani G, Monaco F, Cavo M, Curti A, Isidori A: The Yin and Yang of the Bone Marrow Microenvironment: Pros and Cons of Mesenchymal Stromal Cells in Acute Myeloid Leukemia. Frontiers in Oncology 2019, 9(1135).

5. Forte D, Krause DS, Andreeff M, Bonnet D, Mendez-Ferrer S: Updates on the hematologic tumor microenvironment and its therapeutic targeting. Haematologica 2019, 104(10):1928-1934.

6. Akwii RG, Sajib MS, Zahra FT, Mikelis CM: Role of Angiopoietin-2 in Vascular Physiology and Pathophysiology. Cells 2019, 8(5).

7. Rajabi M, Godugu K, Sudha T, Bharali DJ, Mousa SA: Triazole Modified Tetraiodothyroacetic Acid Conjugated to Polyethylene Glycol: High Affinity Thyrointegrin av $\beta 3$ Antagonist with Potent Anticancer Activities in Glioblastoma Multiforme. Bioconjugate Chemistry 2019, 30(12):3087-3097.

8. Bridoux A, Khan RA, Chen C, Chevé G, Cui H, Dyskin E, Yasri A, Mousa SA: Design, synthesis, and biological evaluation of bifunctional thyrointegrin inhibitors: new anti-angiogenesis analogs. Journal of enzyme inhibition and medicinal chemistry 2011, 26(6):871-882.

9. Yi H, Zeng D, Shen Z, Liao J, Wang X, Liu Y, Zhang X, Kong P: Integrin alphavbeta3 enhances $\beta$-catenin signaling in acute myeloid leukemia harboring Fms-like tyrosine kinase-3 internal tandem duplication mutations: implications for microenvironment influence on sorafenib sensitivity. Oncotarget 2016, 7(26):40387-40397.

10. Jiang X, Mak PY, Mu H, Tao W, Mak DH, Kornblau S, Zhang Q, Ruvolo P, Burks JK, Zhang W et al: Disruption of Wnt/ $\beta$-Catenin Exerts Antileukemia Activity and Synergizes with FLT3 Inhibition in FLT3-Mutant Acute Myeloid Leukemia. Clinical cancer research : an official journal of the American Association for Cancer Research 2018, 24(10):2417-2429.

11. Hosseini A, Ghorbanmehr N, Valojerdi MR, Bakhtiyari M, Movaghar B: Leukaemia inhibitory factor increases av $\beta 3$ integrin expression in cultured mouse blastocysts. Reproduction, Fertility and Development 2020, 32(13):1116-1124.

12. Kuželová K, Obr A, Marková J, Gašová Z: Integrin expression and adhesivity to fibronectin in primary acute myeloid leukemia cells: Impact of NPM1 and FLT3 mutations. European Journal of Haematology 2020, 105(5):578-587.

13. Cheng SY, Leonard JL, Davis PJ: Molecular aspects of thyroid hormone actions. Endocr Rev 2010, 31(2):139-170.

14. Davis PJ, Davis FB, Mousa SA, Luidens MK, Lin HY: Membrane receptor for thyroid hormone: physiologic and pharmacologic implications. Annual review of pharmacology and toxicology 2011, 51:99-115.

15. Davis PJ, Goglia F, Leonard JL: Nongenomic actions of thyroid hormone. Nature reviews Endocrinology 2016, 12(2):111-121.

16. Hay BA, Godugu K, Darwish NHE, Fujioka K, Sudha T, Karakus OO, Mousa SA: New Thyrointegrin avß3 Antagonist with a Scalable Synthesis, Brain Penetration, and Potent Activity against Glioblastoma Multiforme. Journal of Medicinal Chemistry 2021.

17. Wu SQ, Voelkerding KV, Sabatini L, Chen XR, Huang J, Meisner LF: Extensive amplification of bcr/abl fusion genes clustered on three marker chromosomes in human leukemic cell line K-562. Leukemia 1995, 9(5):858-862. 
18. Tang C, Schafranek L, Watkins DB, Parker WT, Moore S, Prime JA, White DL, Hughes TP: Tyrosine kinase inhibitor resistance in chronic myeloid leukemia cell lines: investigating resistance pathways. Leuk Lymphoma 2011, 52(11):2139-2147.

19. Koeffler HP, Billing R, Lusis AJ, Sparkes R, Golde DW: An undifferentiated variant derived from the human acute myelogenous leukemia cell line (KG-1). Blood 1980, 56(2):265-273.

20. Kouns WC, Hadvary P, Haering P, Steiner B: Conformational modulation of purified glycoprotein (GP) IIb-Illa allows proteolytic generation of active fragments from either active or inactive GPIIb-Illa. J Biol Chem 1992, 267(26):18844-18851.

21. Glinsky GV, Berezovska O, Glinskii AB: Microarray analysis identifies a death-from-cancer signature predicting therapy failure in patients with multiple types of cancer. J Clin Invest 2005, 115(6):1503-1521.

22. Chen EY, Tan CM, Kou Y, Duan Q, Wang Z, Meirelles GV, Clark NR, Ma'ayan A: Enrichr: interactive and collaborative HTML5 gene list enrichment analysis tool. BMC bioinformatics 2013, 14:128.

23. Kuleshov MV, Jones MR, Rouillard AD, Fernandez NF, Duan Q, Wang Z, Koplev S, Jenkins SL, Jagodnik KM, Lachmann A et al: Enrichr: a comprehensive gene set enrichment analysis web server 2016 update. Nucleic acids research 2016, $44(\mathrm{~W} 1)$ :W90-97.

24. Glinsky GV: Human-specific genomic features of pluripotency regulatory networks link NANOG with fetal and adult brain development. bioRxiv 2017:022913.

25. Glinsky G, Barakat TS: The evolution of Great Apes has shaped the functional enhancers' landscape in human embryonic stem cells. Stem Cell Research 2019, 37:101456.

26. Glinsky GV: A Catalogue of 59,732 Human-Specific Regulatory Sequences Reveals Unique-to-Human Regulatory Patterns Associated with Virus-Interacting Proteins, Pluripotency, and Brain Development. DNA Cell Bio/ 2020, 39(1):126-143.

27. Glinsky GV: Impacts of genomic networks governed by human-specific regulatory sequences and genetic loci harboring fixed human-specific neuro-regulatory single nucleotide mutations on phenotypic traits of modern humans. Chromosome research : an international journal on the molecular, supramolecular and evolutionary aspects of chromosome biology 2020:1-24.

28. Rajabi M, Godugu K, Sudha T, Bharali DJ, Mousa SA: Triazole Modified Tetraiodothyroacetic Acid Conjugated to Polyethylene Glycol: High Affinity Thyrointegrin a(v)B(3) Antagonist with Potent Anticancer Activities in Glioblastoma Multiforme. Bioconjug Chem 2019, 30(12):3087-3097.

29. Mousa SA, Glinsky GV, Lin H-Y, Ashur-Fabian O, Hercbergs A, Keating KA, Davis PJ: Contributions of Thyroid Hormone to Cancer Metastasis. Biomedicines 2018, 6(3):89.

30. Mousa S, Sudha T, Godugu K, Rajabi M, Sell S, Davis P: Abstract 1300: Novel thyrointegrin $\pm y^{2} 3$ antagonist in the treatment of glioblastoma multiforme. Cancer Research 2019, 79:1300-1300.

31. Chin Y-T, He Z-R, Chen C-L, Chu H-C, Ho Y, Su P-Y, Yang Y-CSH, Wang K, Shih Y-J, Chen Y-R et al: Tetrac and NDAT Induce Antiproliferation via Integrin av $\beta 3$ in Colorectal Cancers With Different K-RAS Status. Front Endocrinol (Lausanne) 2019, 10:130-130.

32. Sudha T, Bharali DJ, Sell S, Darwish NHE, Davis PJ, Mousa SA: Nanoparticulate Tetrac Inhibits Growth and Vascularity of Glioblastoma Xenografts. Horm Cancer 2017, 8(3):157-165.

33. Davis PJ, Tang H-Y, Hercbergs A, Lin H-Y, Keating KA, Mousa SA: Bioactivity of Thyroid Hormone Analogs at Cancer Cells. Front Endocrinol (Lausanne) 2018, 9:739-739.

34. Lin H-Y, Glinsky GV, Mousa SA, Davis PJ: Thyroid hormone and anti-apoptosis in tumor cells. Oncotarget 2015, 6(17):14735-14743.

35. Yalcin M, Bharali DJ, Lansing L, Dyskin E, Mousa SS, Hercbergs A, Davis FB, Davis PJ, Mousa SA: Tetraidothyroacetic acid (tetrac) and tetrac nanoparticles inhibit growth of human renal cell carcinoma xenografts. Anticancer research 2009, $29(10): 3825-3831$.

36. Yalcin M, Lin HY, Sudha T, Bharali DJ, Meng R, Tang HY, Davis FB, Stain SC, Davis PJ, Mousa SA: Response of human pancreatic cancer cell xenografts to tetraiodothyroacetic acid nanoparticles. Horm Cancer 2013, 4(3):176-185.

37. Bharali DJ, Yalcin M, Davis PJ, Mousa SA: Tetraiodothyroacetic acid-conjugated PLGA nanoparticles: a nanomedicine approach to treat drug-resistant breast cancer. Nanomedicine (Lond) 2013, 8(12):1943-1954.

38. Ma P, Xing M, Han L, Gan S, Ma J, Wu F, Huang Y, Chen Y, Tian W, An C et al: High PD-L1 expression drives glycolysis via an Akt/mTOR/HIF-1a axis in acute myeloid leukemia. Oncol Rep 2020, 43(3):999-1009.

39. Jabari M, Allahbakhshian Farsani M, Salari S, Hamidpour M, Amiri V, Mohammadi MH: Hypoxia-Inducible Factor1-A (HIF1a) and Vascular Endothelial Growth Factor-A (VEGF-A) Expression in De Novo AML Patients. Asian Pac J Cancer Prev 2019, 20(3):705-710.

40. Abdul-Aziz AM, Shafat MS, Sun Y, Marlein CR, Piddock RE, Robinson SD, Edwards DR, Zhou Z, Collins A, Bowles KM et al: HIF1a drives chemokine factor pro-tumoral signaling pathways in acute myeloid leukemia. Oncogene 2018, 37:2676-2686. 
41. Raffel S, Falcone M, Kneisel N, Hansson J, Wang W, Lutz C, Bullinger L, Poschet G, Nonnenmacher Y, Barnert A et al: BCAT1 restricts aKG levels in AML stem cells leading to IDHmut-like DNA hypermethylation. Nature 2017, 551(7680):384-388.

42. Migliavacca J, Percio S, Valsecchi R, Ferrero E, Spinelli A, Ponzoni M, Tresoldi C, Pattini L, Bernardi R, Coltella N: Hypoxia inducible factor-1a regulates a pro-invasive phenotype in acute monocytic leukemia. Oncotarget 2016, 7(33):53540-53557.

43. Gao XN, Yan F, Lin J, Gao L, Lu XL, Wei SC, Shen N, Pang JX, Ning QY, Komeno Y et al: AML1/ETO cooperates with HIF1a to promote leukemogenesis through DNMT3a transactivation. Leukemia 2015, 29(8):1730-1740.

44. Wang X, Sun D, Tai J, Chen S, Yu M, Ren D, Wang L: TFAP2C promotes stemness and chemotherapeutic resistance in colorectal cancer via inactivating hippo signaling pathway. Journal of Experimental \& Clinical Cancer Research 2018, $37(1): 27$.

45. Chen D, Liu W, Zimmerman J, Pastor WA, Kim R, Hosohama L, Ho J, Aslanyan M, Gell JJ, Jacobsen SE et al: The TFAP2C-Regulated OCT4 Naive Enhancer Is Involved in Human Germline Formation. Cell Rep 2018, 25(13):3591-3602.e3595.

46. Kang J, Kim W, Lee S, Kwon D, Chun J, Son B, Kim E, Lee JM, Youn H, Youn B: TFAP2C promotes lung tumorigenesis and aggressiveness through miR-183- and miR-33a-mediated cell cycle regulation. Oncogene 2017, 36(11):1585-1596.

47. Do H, Kim D, Kang J, Son B, Seo D, Youn H, Youn B, Kim W: TFAP2C increases cell proliferation by downregulating GADD45B and PMAIP1 in non-small cell lung cancer cells. Biol Res 2019, 52(1):35-35.

48. Pastor WA, Liu W, Chen D, Ho J, Kim R, Hunt TJ, Lukianchikov A, Liu X, Polo JM, Jacobsen SE et al: TFAP2C regulates transcription in human naive pluripotency by opening enhancers. Nat Cell Biol 2018, 20(5):553-564.

49. Kim W, Kim E, Lee S, Kim D, Chun J, Park KH, Youn H, Youn B: TFAP2C-mediated upregulation of TGFBR1 promotes lung tumorigenesis and epithelial-mesenchymal transition. In: Exp Mol Med. vol. 48; 2016: e273.

50. Shousha WG, Ramadan SS, El-Saiid AS, Abdelmoneim AE, Abbas MA: Expression and clinical significance of SNAI1 and ZEB1 genes in acute myeloid leukemia patients. Molecular biology reports 2019, 46(4):4625-4630.

51. Carmichael CL, Wang J, Nguyen T, Kolawole O, Benyoucef A, De Maziere C, Milne AR, Samuel S, Gillinder K, Hediyeh-Zadeh S et al: The EMT modulator SNAI1 contributes to AML pathogenesis via its interaction with LSD1. Blood 2020, 136(8):957-973.

52. Carmichael CL, Wang J, Nguyen T, Kolawole O, Benyoucef A, De Mazière C, Milne AR, Samuel S, Gillinder K, Hediyeh-Zadeh S et al: The EMT modulator SNAI1 contributes to AML pathogenesis via its interaction with LSD1. Blood 2020, 136(8):957-973.

53. Tian WL, Guo R, Wang F, Jiang ZX, Tang P, Huang YM, Sun L: The IRF9-SIRT1-P53 axis is involved in the growth of human acute myeloid leukemia. Experimental cell research 2018, 365(2):185-193.

54. Patnaik MM, Lasho T, Howard M, Finke C, Ketterling RL, Al-Kali A, Pardanani A, Droin N, Gangat N, Tefferi A et al: Biallelic inactivation of the retinoblastoma gene results in transformation of chronic myelomonocytic leukemia to a blastic plasmacytoid dendritic cell neoplasm: shared clonal origins of two aggressive neoplasms. Blood Cancer Journal 2018, 8(9):82.

55. Su L, Tan Y, Lin H, Liu X, Yu L, Yang Y, Liu S, Bai O, Yang Y, Jin F et al: Mutational spectrum of acute myeloid leukemia patients with double CEBPA mutations based on next-generation sequencing and its prognostic significance. Oncotarget 2018, 9(38):2497024979 .

56. Watanabe T, Oyama T, Asada M, Harada D, Ito Y, Inagawa M, Suzuki Y, Sugano S, Katsube K-i, Karsenty G et al: MAML1 enhances the transcriptional activity of Runx2 and plays a role in bone development. PLoS Genet 2013, 9(1):e1003132-e1003132.

57. Hsieh MT, Wang LM, Changou CA, Chin YT, Yang YSH, Lai HY, Lee SY, Yang YN, Whang-Peng J, Liu LF et al: Crosstalk between integrin av $\beta 3$ and ERa contributes to thyroid hormone-induced proliferation of ovarian cancer cells. Oncotarget 2017, 8(15):2423724249.

58. Davis PJ, Mousa SA, Cody V, Tang HY, Lin HY: Small molecule hormone or hormone-like ligands of integrin aV $\beta 3$ : implications for cancer cell behavior. Horm Cancer 2013, 4(6):335-342.

59. Lin HY, Su YF, Hsieh MT, Lin S, Meng R, London D, Lin C, Tang HY, Hwang J, Davis FB et al: Nuclear monomeric integrin av in cancer cells is a coactivator regulated by thyroid hormone. FASEB journal : official publication of the Federation of American Societies for Experimental Biology 2013, 27(8):3209-3216.

60. Meng R, Tang HY, Westfall J, London D, Cao JH, Mousa SA, Luidens M, Hercbergs A, Davis FB, Davis PJ et al: Crosstalk between integrin av $\beta 3$ and estrogen receptor-a is involved in thyroid hormone-induced proliferation in human lung carcinoma cells. PloS one 2011, 6(11):e27547.

61. M MSaR: Non-cleavable polymer conjugated with alpha V beta 3 integrin thyroid antagonists. . In: USA. Edited by Patent U, vol. $10,695,436 ; 2020$.

62. M MSaR: Non-cleavable polymer conjugated with .alpha.V.beta.3 integrin thyroid antagonists. In. Edited by Patent U. USA; 2019. 


\section{Figures}

Figure 1

A<smiles>CC(CCOc1ccc(F)cc1)n1cc(COc2c(I)cc(Oc3c(I)cc(CC(=O)O)cc3I)cc2I)nn1</smiles>

B

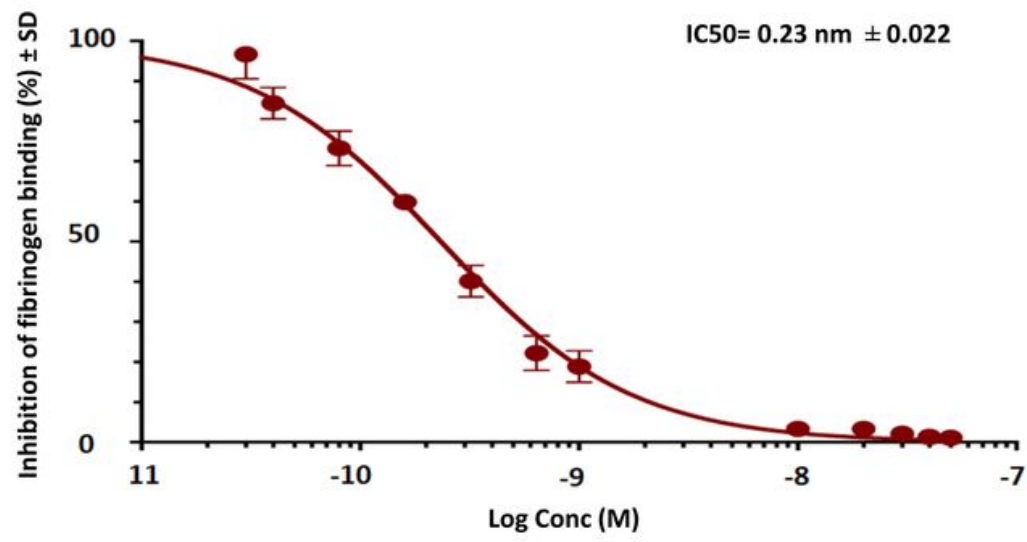

\section{Figure 1}

Binding Affinity of fb-PMT to human Integrin avb3 Receptors. fb-PMT high affinity for the thyrointegrin av $\beta 3$ receptors (Ki $0.23 \mathrm{nM})$ 

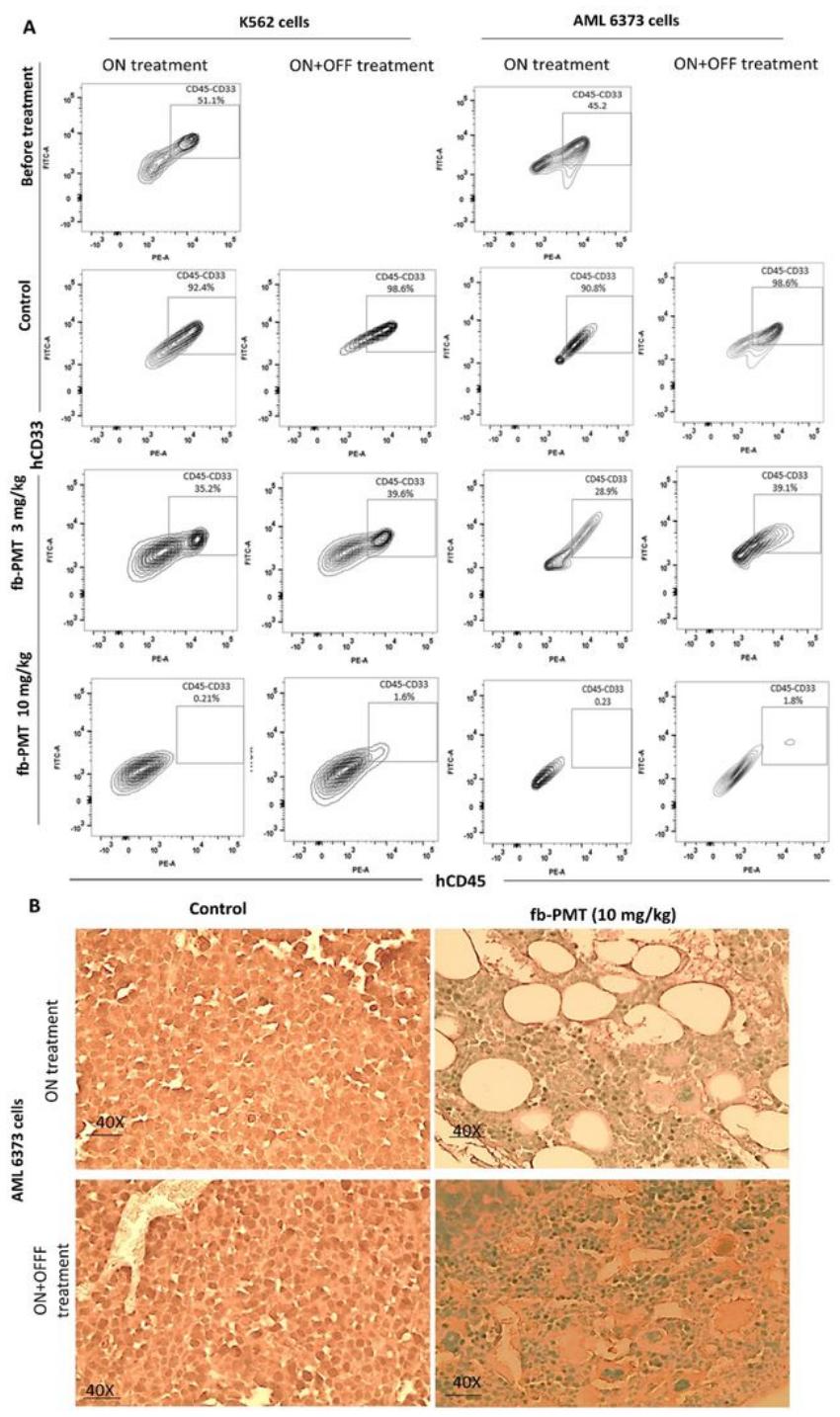

Figure 2

Blood smear from transgenic mice engrafted with leukemic cells A) K562 cells in peripheral blood (PB) cells, control blood smears versus fb-PMT treated mice at different doses. Blast cells appeared in the blood smears of NSG-S mice after 10 days. After 21 days of $\mathrm{fb}-\mathrm{PMT}$ daily subcutaneous injection, the control group showed many blast cells in the peripheral blood, while fb-PMT $(1,3$, and 10 $\mathrm{mg} / \mathrm{kg}$ ) treated mice showed a significant decrease in the blast cells by $35 \%, 65 \%$, and $>95 \%$, respectively. The decrease of blast cell percentage in the peripheral blood was dose-dependent. Left side shows blast cells in peripheral blood in fb-PMT treated animals at different doses ON 21 Days and ON+OFF treatment for 14 days and right side shows representative K562-Luc AML control blood smears versus fb-PMT $(10 \mathrm{mg} / \mathrm{kg}$ ) treated animal cells. Control group showed immature cells with prominent nucleoli (blast cells) in the peripheral blood. fb-PMT (10 mg/kg) treated animal showed segmented neutrophils with absent blast cells, after 21 days of daily subcutaneous injection. fb-PMT (10 mg/kg) maintained remission after 2 weeks discontinuation. B) Primary AML cells (6373-FIT3-ITD), fb-PMT treated at 1,3 , and $10 \mathrm{mg} / \mathrm{kg}$ subcutaneous daily for 28 days and 14 days OFF treatment prevented blast cell expression/reproduction by $54 \%, 75 \%$, and $90.5 \%$, respectively, compared to controls. Right side shows representative image from control group with immature cells and prominent nucleoli (blast cells) in the peripheral blood where fb-PMT (10 mg/kg) treated animal shows segmented neutrophils with absent blast cells. OFF study, 14 days post-treatment, fb-PMT $(10 \mathrm{mg} / \mathrm{kg})$ showed successful maintained remission. 
Figure 3

A
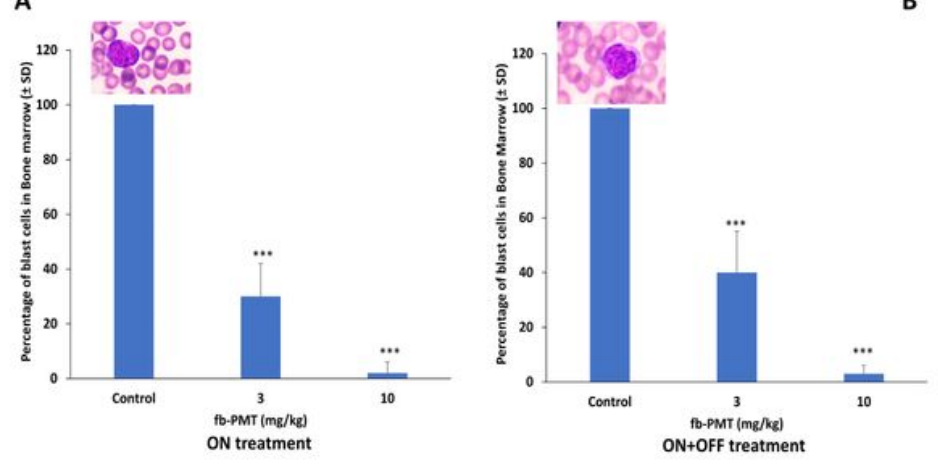

C

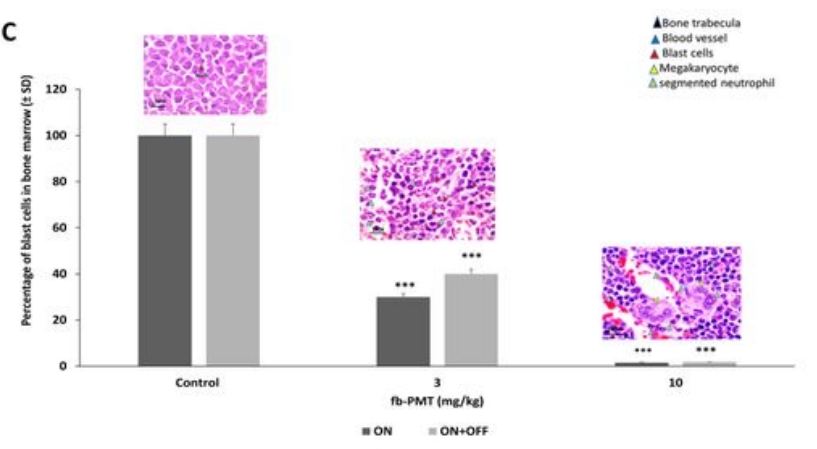

B
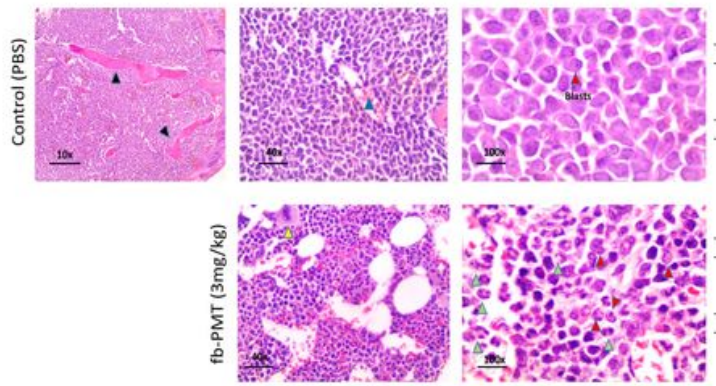

D

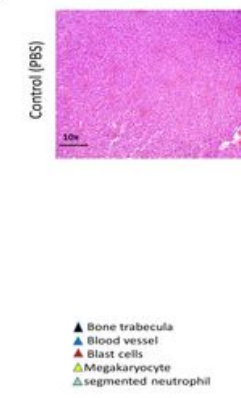

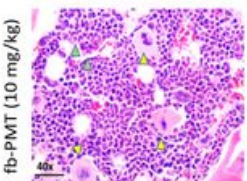

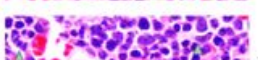

ABone trabecula
Alood vessel
Blast cells A Mezalaryocyte $\Delta$ segmented neutrop

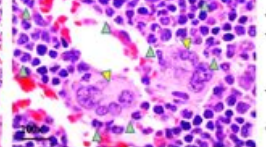

Normocellular BM. blast cells (rounded monotonous cells nucleoli) less than $5 \%$ $>95 \%$ maturation could be detected (segmented neutrophils)
30-40\% infiltration with blast cells nucleus and dark point like nucleolit) $70 \%$ maturation could be detected

\section{Figure 3}

Blast cells in bone marrow. A) Myeloblast in bone marrow of transgenic mice engrafted with K562-Luc cells and after 21 days of treatment (ON treatment) and 14 days post-treatment (ON + OFF treatment). Bone marrow of fb-PMT (3 mg/kg) treated group was associated with $30-40 \%$ infiltration with blast cells, and $70 \%$ maturation could be detected. fb-PMT (10 mg/kg) treated group presented with blast cells $<5 \%$ and $90-95 \%$ normal maturation (segmented neutrophils). ON+OFF treatment, fb-PMT (10 mg/kg) showed maintained remission. B) Histopathological evaluation of bone marrow of transgenic mice engrafted with K562-Luc cells (ON+OFF treatment). Myeloblast in bone marrow of transgenic mice after 21 days of treatment. Bone marrow of fb-PMT (3 mg/kg) treated group was associated with $30-40 \%$ infiltration with blast cells, and $70 \%$ maturation could be detected. fb-PMT (10 mg/kg) treated group presented with blast cells $<5 \%$ and $90-95 \%$ normal maturation (segmented neutrophils). C) Myeloblast in bone marrow from transgenic mice engrafted with primary AML cells (6373-FIT3-ITD) control versus fb-PMT treated animal through 28 days and 14 days posttreatment. More than $20 \%$ immature blast cells in marrow smears is characteristic of AML. Treated group (10 mg/kg) was associated with $>90 \%$ decrease in leukemic cells burden. The ON+OFF group showed sustained remission with fb-PMT (10 mg/kg) after 14 days.

D) Histopathological evaluation of bone marrow in transgenic mice engrafted with primary AML cells (6373-FIT3-ITD) control versus fbPMT treated animal through 28 days and 14 days post-treatment. Bone marrow of fb-PMT ( $3 \mathrm{mg} / \mathrm{kg})$ treated group was associated with $35 \%$ infiltration with blast cells, and $60-70 \%$ maturation could be detected. The fb-PMT (10 mg/kg) treated group presented with blast cells $<5 \%$ and $>95 \%$ normal maturation (segmented neutrophils), (***P<0.0001, $\left.{ }^{*} P<0.001,{ }^{*} P<0.01\right)$. 
Figure 4
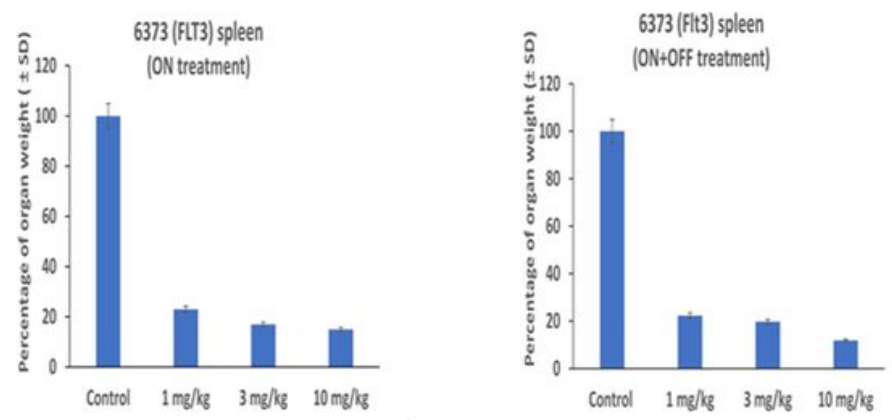

A
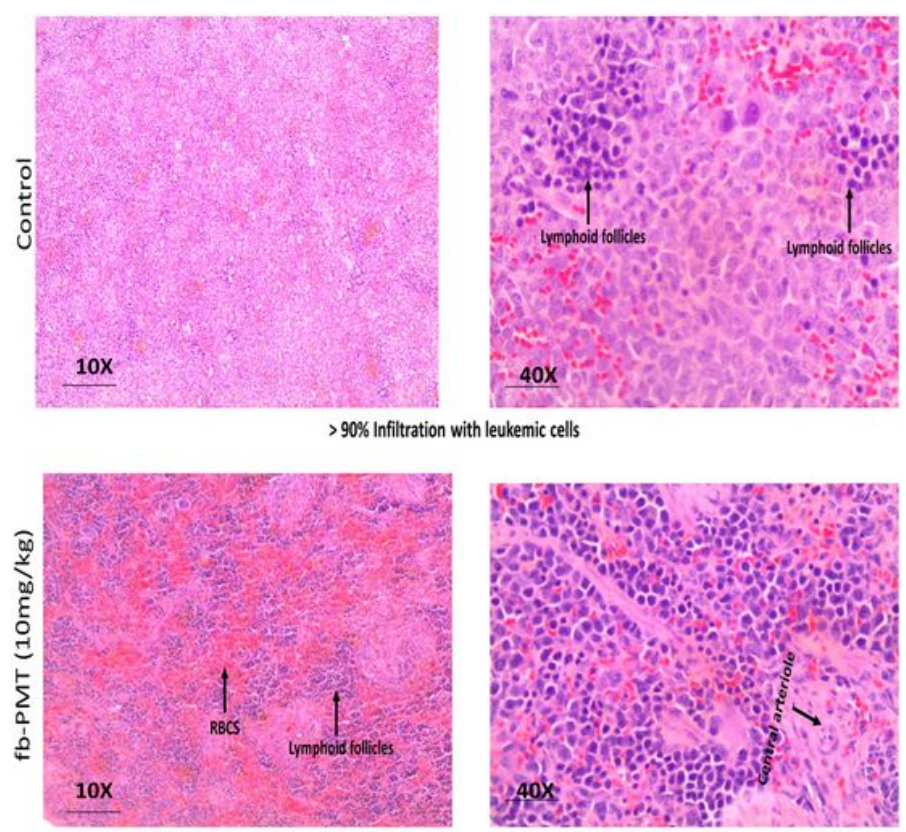

- Lymphoid follicles (Clusters of lymphocytes)

- RBCs more abundant
- Blast $\angle 5 \%$

B

\section{Figure 4}

Evaluation of leukemic cells infiltration of spleen. A) Evaluation of splenic infiltration of leukemic cells in transgenic mice engrafted with primary AML cells (6373-FIT3-ITD) control versus fb-PMT treated animal through 28 days and 14 days post-treatment. The splenic weight shows marked decrease in weight ( $80 \%)$ even with the low dose fb-PMT (1 mg/kg). ON+OFF groups showed maintained normal splenic weight in comparison to control, which may reflect successful prevention of engraftment. B) Histopathological evaluation of splenic infiltration with primary AML cells in fb-PMT treated $(10 \mathrm{mg} / \mathrm{kg}$ ) versus control group. Upper row (control group) shows $90-95 \%$ Infiltration with leukemic cells. Lower row (fb-PMT, $10 \mathrm{mg} / \mathrm{kg}$ ) shows multiple normal lymphoid follicles with leukemic cells infiltration 5$10 \%$. 
Figure 5
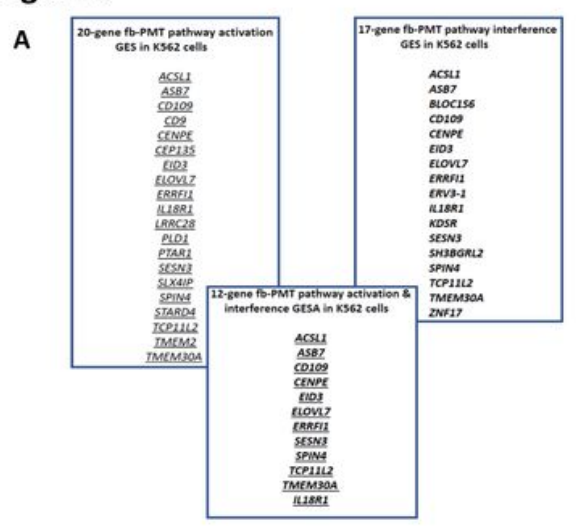

25-gene fb-PMT gene expression signature in K562 cells

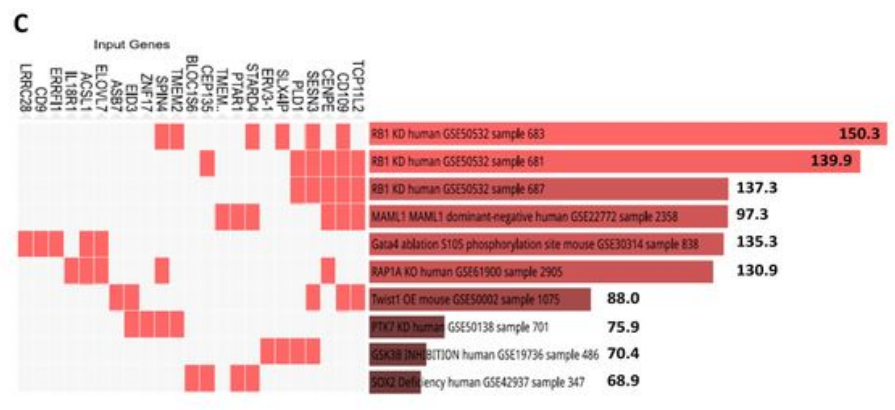

Database: Gene perturbations from GEO up-regulation

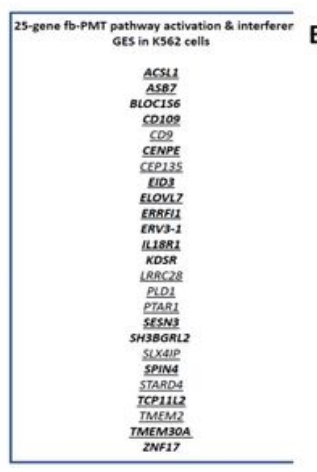

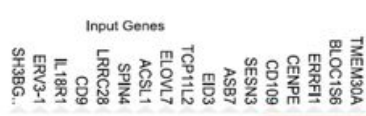

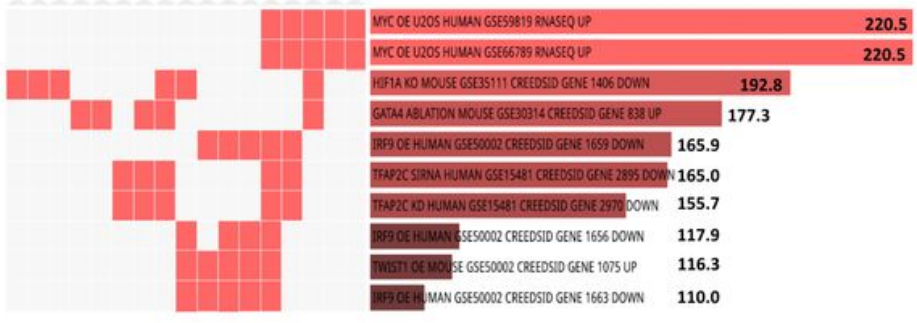

Database: TF perturbations followed by expression

25-gene fb-PMT gene expression signature in K562 cells

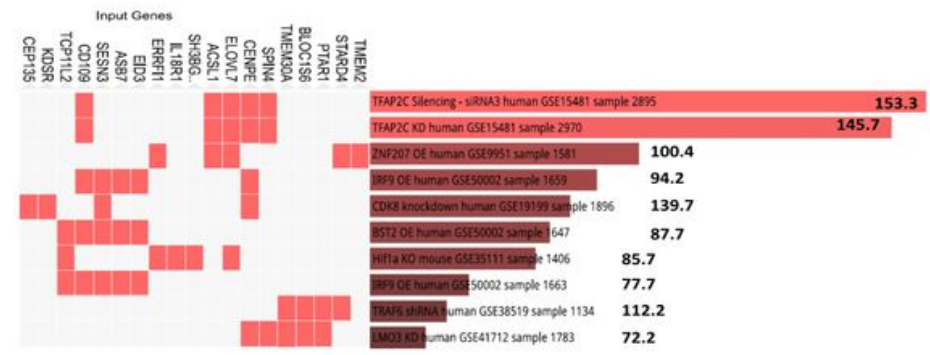

Database: Gene perturbations from GEO down-regulation

Figure 5

Identification and characterization of the 25-gene fb-PMT-induced expression signature in K562 cells. A) Integration into different functional categories of fb-PMT treatment-induced gene expression signatures (GES) as reported in Table 1. B) GSEA of 25-gene GES using the TF perturbations followed by expression database. C) GSEA of 25-gene GES using the Gene perturbations from gene expression omnibus (GEO) database focused on up-regulated genes. D) GSEA of 25-gene GES using the GEO database focused on down-regulated genes. Numbers shown next to the bar graphs report the values of Cumulative scores (Methods). 
Figure 6

A

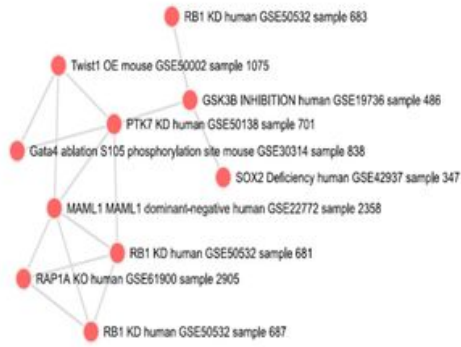

Database: Gene perturbations from GEO up-regulation

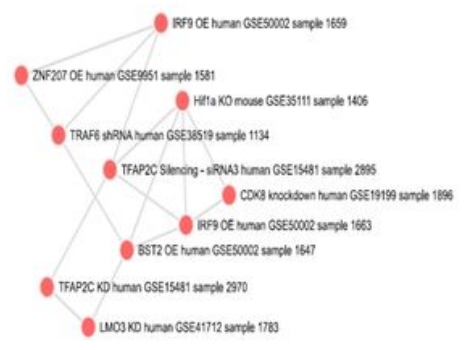

Database: Gene perturbations from GEO down-regulation
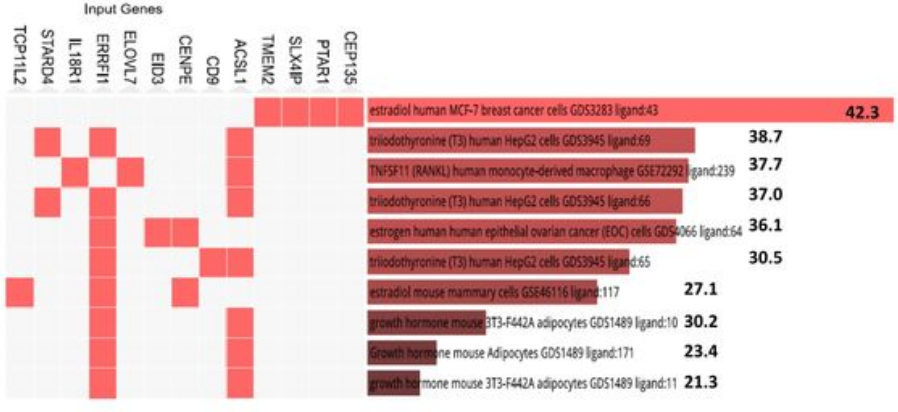

Database: Ligand perturbations from GEO up-regulation 25-gene fb-PMT gene expression signature in K562 cells

C
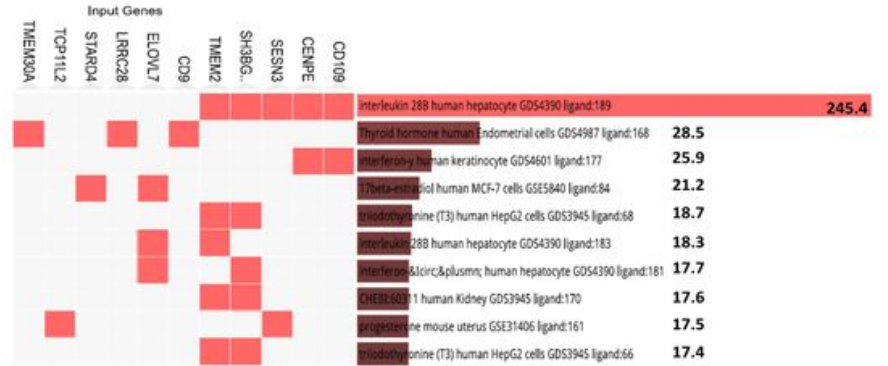

Database: Ligand perturbations from GEO down-regulation

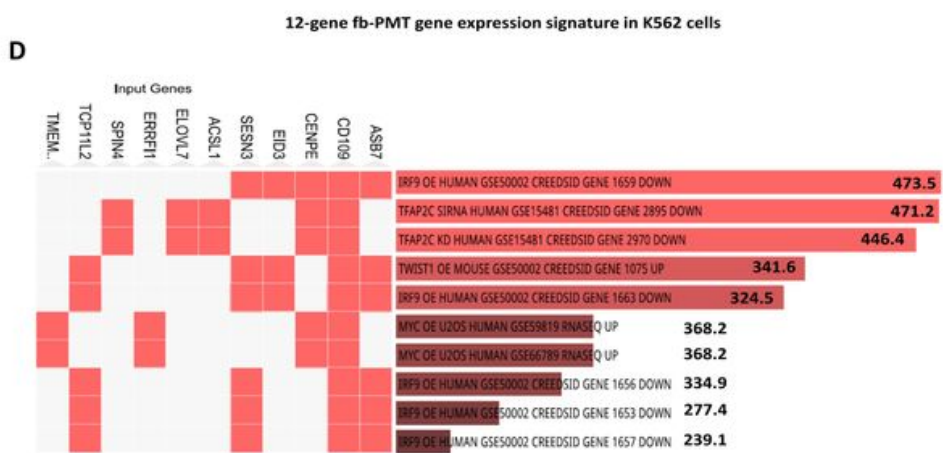

Database: TF perturbations followed by expression

Figure 6

Networks and Ligands associated with the 25-gene fb-PMT-induced expression signature in K562 cells. A) Affected genomic regulatory networks revealed by the GSEA of the Gene perturbations from gene expression omnibus (GEO) database focused on up-regulated (left) and down-regulated (right) genes. B) GSEA of the Ligand perturbations from GEO database focused on up-regulated genes. C) GSEA of the Ligand perturbations from GEO database focused on down-regulated genes. Numbers shown next to the bar graphs report the values of Cumulative scores (Methods). D) fb-PMT gene expression signature in K562 cells 
Figure 7

A

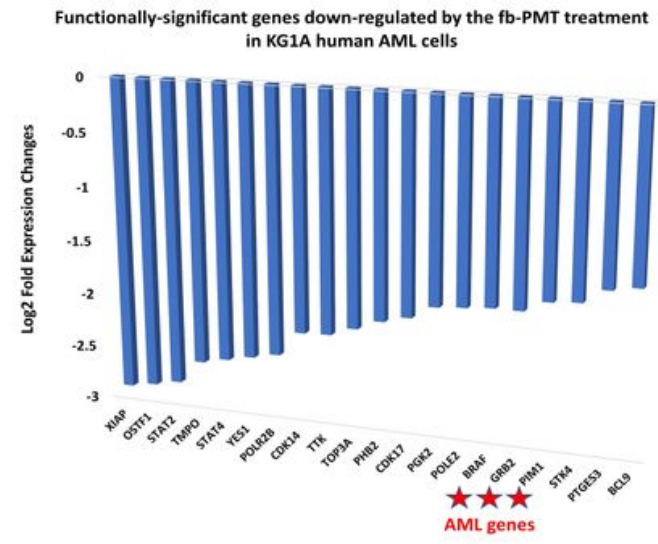

genes down-regulated by the fb-PMT treatment

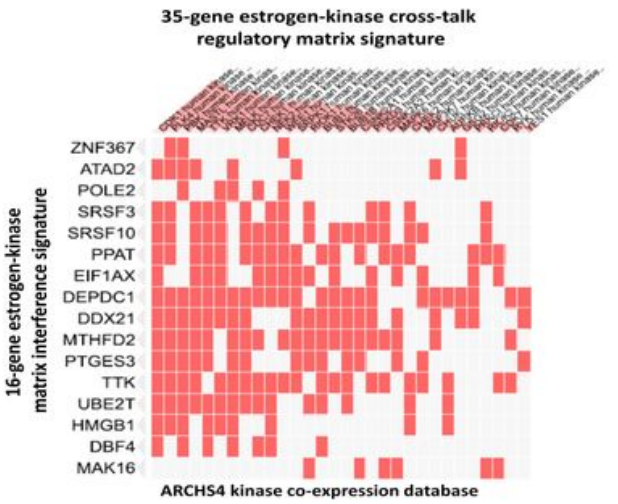

69-gene estrogen pathway interference signature harbors 16-gene estrogen-kinase cross-talk signature

B

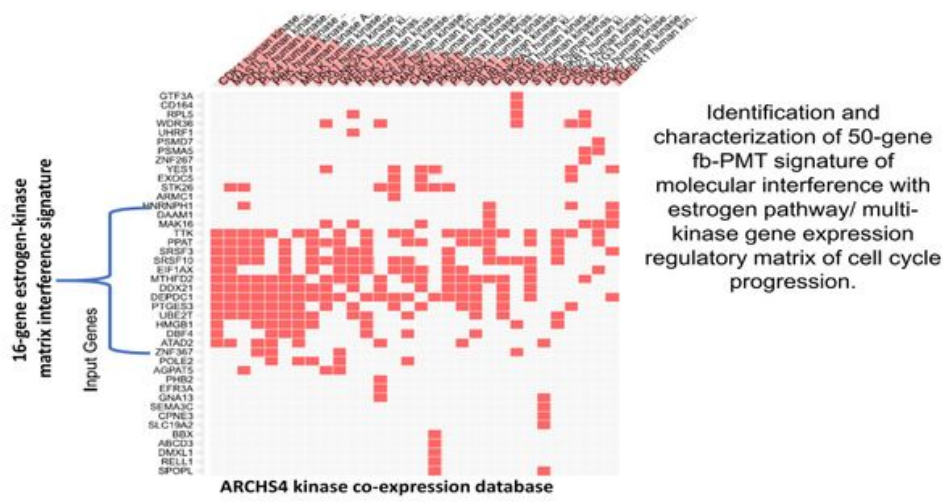

D

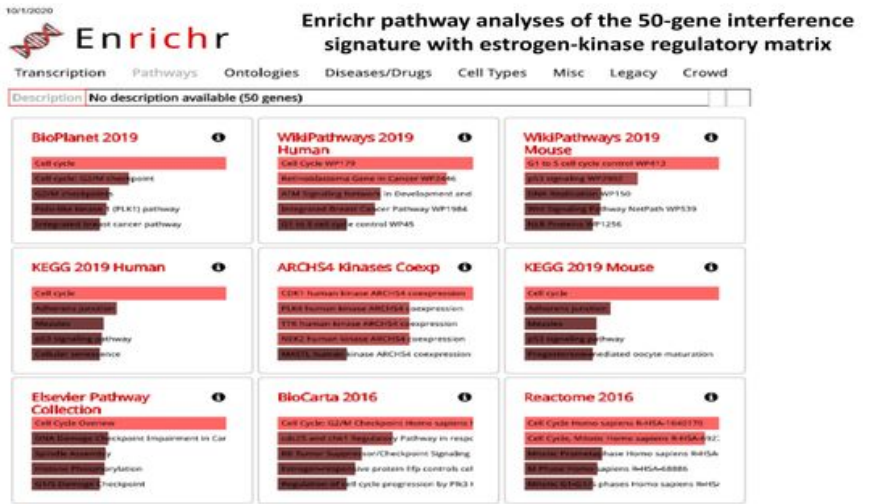

Figure 7

Examples of the specific genes and pathways of potential functional significance revealed by the GSEA of 233 genes down-regulated in KG1a cells after fb-PMT treatment. A) Functionally significant genes down-regulated by fb-PMT treatment in KG1a human AML cells. B) GSEA of the TF Perturbations Followed by Expression database (top 30 of 84 significant records). C) GSEA of the LINCS L1000 Ligand Perturbations database of up-regulated genes revealed evidence of molecular interference with functions of multiple growth factors in human cancer cell lines. D) GSEA of the KEGG 2019 Human database revealed evidence of targeting multiple cancer pathways (including AML).

\section{Supplementary Files}

This is a list of supplementary files associated with this preprint. Click to download.

- Suppl.file.docx 